\title{
MiR-181a contributes to bufalin-induced apoptosis in PC-3 prostate cancer cells
}

\author{
Xiao-feng Zhai ${ }^{1 \dagger}$, Fan-fu Fang ${ }^{2 \dagger}$, Qun Liu ${ }^{1 \dagger}$, Yong-bin Meng ${ }^{1}$, Yu-yu Guo ${ }^{1}$ and Zhe Chen ${ }^{*}$
}

\begin{abstract}
Background: Bufalin is a major active compound of cinobufacini, which comes from dried toad venom and has been used for treatments of various cancers in China for many years. A number of studies have demonstrated that bufalin can induce apoptosis in some cancers. However, effects and mechanism of bufalin on prostate cancer cells remain unknown.

Methods: Apoptosis assay was measured by the annexin-V/PI flow cytometric assay. Western blot was used to measure Caspase-3 and BCl-2. qRT-PCR was used to measure the relative expression of miR-181a.

Results: Bufalin was found to induce the expression of miR-181a, a small non-coding RNA believed to induce apoptosis by repressing its target gene, BCL-2. In prostate cancer PC-3cell line, bufalin-induced apoptosis can be largely attenuated by a miR-181a inhibitor, which blocked bufalin-induced $\mathrm{BCl}-2$ reduction and caspase-3 activation.

Conclusions: Our dataindicatedthat miR-181a mediates bufalin-induced apoptosis in PC-3 cells. Thus, we presented here a new pharmacological mechanism for bufalin in anti-tumor therapy.
\end{abstract}

Keywords: miR-181a, Bufalin, Apoptosis, Prostate cancer, Traditional Chinese medicine

\section{Background}

Cinobufacini is extracted from the skins and parotid venom glands of the toad Bufo bufo gargarizans cantor and has been widely used in clinical therapy for various cancers in China. The major pharmacologic constituents of cinobufacini are bufadienolides (which primarily include bufalin, cinobufagin, resibufogenin, bufotalin and lumichrome), alkaloids, biogenic amines, peptides and proteins [1]. Studies have suggested that some of its active compounds (e.g., bufalin and cinobufagin) exhibit significant antitumor activity, including inhibition of cell proliferation, induction of cell differentiation, induction of apoptosis, disruption of the cell cycle, inhibition of cancer angiogenesis, reversal of multi-drug resistance, and regulation of the immune response [2]. The mechanism of bufalin-induced apoptosis has been well investigated in various cancer cells. For example, bufalin was shown to induce apoptosis of human gastric cancer cells by inhibiting

\footnotetext{
* Correspondence: chenzhech@163.com

${ }^{\dagger}$ Equal contributors

'Department of Integrative Oncology, Changhai Hospital of Traditional Chinese Medicine, Second Military Medical University, Shanghai 200433, China

Full list of author information is available at the end of the article
}

the PI3K/Akt signaling pathway [3]. In prostate cancer cells, bufalin significantly induces apoptosis through the p53- and Fas-mediated apoptotic pathways [4]. Bufalin was shown to induce ROS-mediated Bax translocation, mitochondrial permeability transition, and caspase- 3 activation in human lung adenocarcinoma cells [5]. In an orthotopic transplantation tumor model of human hepatocellular carcinoma, bufalin showed significant anticancer action by regulating expression of apoptosis-related proteins, Bcl-2 and Bax [6]. Similarly, Takai et al. showed that bufalin-induced apoptosis was associated with levels of $\mathrm{Bcl}-2, \mathrm{Bcl}-\mathrm{XL}$ and caspase-9 in human endometrial and ovarian cancer cells [7].

MicroRNAs (miRNAs) are small, endogenous non-coding RNA molecules of $\sim 22$ nucleotides (nt) in length that can regulate gene expression. MiRNAs recognize and repress target mRNAs based on sequence complementarity, and are critical in regulating a variety of biological processes, including cell cycle, differentiation, development, and metabolism, as well as such diseases as diabetes, immunoor neurodegenerative disorders, and cancer [8]. In cancer, miRNAs function as regulatory molecules, acting as
C Biomed Central

(c) 2013 Zhai et al.; licensee BioMed Central Ltd. This is an open access article distributed under the terms of the Creative Commons Attribution License (http://creativecommons.org/licenses/by/2.0), which permits unrestricted use, distribution, and reproduction in any medium, provided the original work is properly cited. 


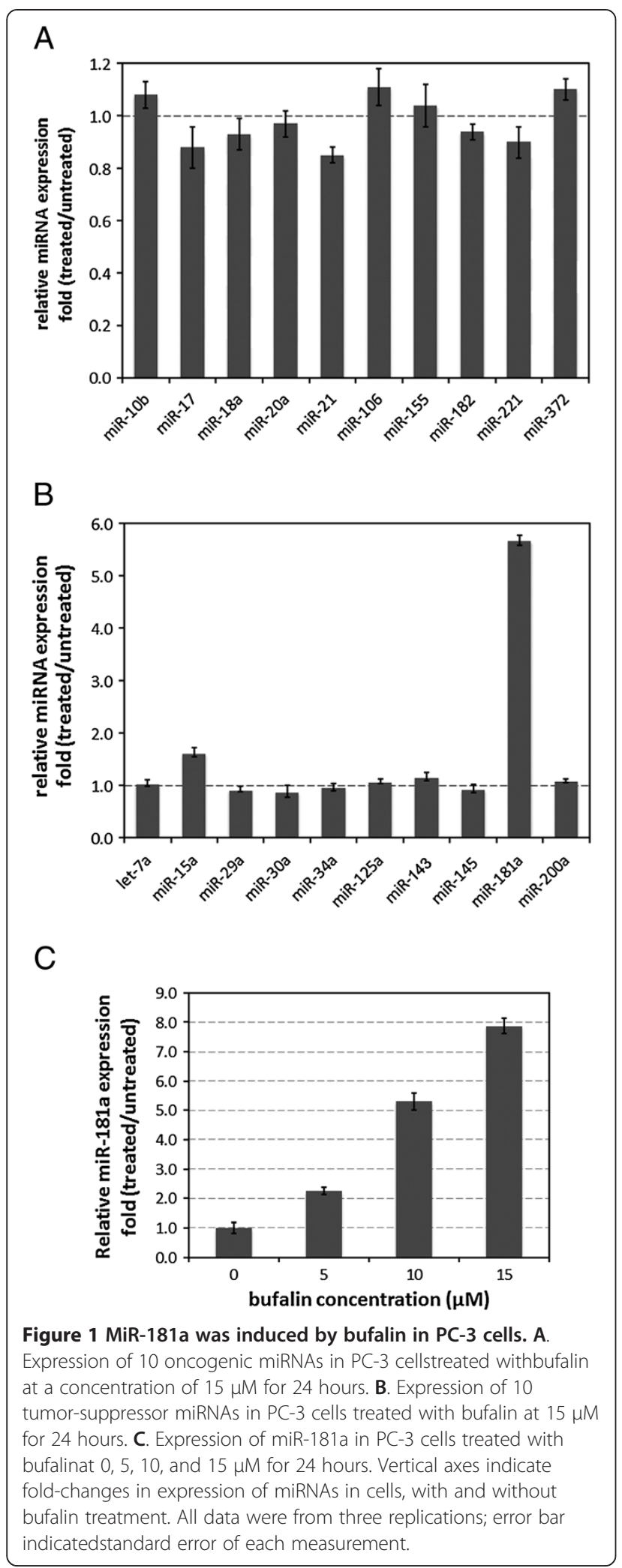

oncogenes or tumor suppressors. Dysregulation of these miRNAs contributes to tumorigenesis by stimulating proliferation, angiogenesis and invasion [9-11].
MiR-181 was first identified in promoting B-cell differentiation when expressed in hematopoietic stem/progenitor cells [12]. Subsequently, the miR-181 family (miR-181a and miR-181b) was shown to function as tumor suppressors that triggered growth inhibition, induced apoptosis and inhibited invasion in glioma cells [13]. Ouyang et al. showed miR-181 to induce apoptosis by targeting multiple Bcl-2 family members in astrocytes [14]. Recently, several studies further showed that by targeting various multiple anti-apoptosisgenes, such as $B C L-2, \mathrm{miR}-181$ significantly enhances drug- or radiation-induced apoptosis in various cancer cells [15-20]. In chronic myeloid leukemia (CML), the RalA gene was reported as a direct target of miR-181a, and is associated with cell proliferation, $G_{2}$-phase arrest and apoptosis [21].

Here, we report that bufalin treatment could induce miR-181a expression. We also show that miR-181a contributes to bufalin-induced apoptosis in prostate cancer cells. Thus, our study illustrated a new pharmacological mechanism for bufalin in anti-tumor therapy.

\section{Methods}

\section{Cell culture and treatment}

Human prostate carcinoma PC-3 cells were maintained in Ham's F-12 medium (Invitrogen, Carlsbad, CA, USA) supplemented with $10 \%$ fetal bovine serum (Invitrogen, Carlsbad, CA, USA). Bufalin (Sigma-Aldrich, St. Louis, MO, USA) was dissolved in DMSO and stocked in $1 \mathrm{mM}$ solution. Cells with $80-90 \%$ confluence in 12-well plates were treated with indicated concentrations of bufalinfor 24 hours. When combined with miR-181a inhibitor, 50 or $100 \mu \mathrm{M}$ of miR-181a inhibitor was transfectedinto cells ( $70 \%$ confluence in 12-well plates) 12 hours before bufalin treatment. MiR-181a, miR-NC and their inhibitors were purchased from GenePharma (GenePharma, Shanghai, China). Sequence of miR-NC was from C. elegansand has no known similar sequence in the human genome. Transfection was performed using Lipofectamine ${ }^{\mathrm{TM}}$ RNAiMAX (Invitrogen, Carlsbad, CA, USA).

\section{RNA isolation and quantitative real-time PCR}

Total RNA was isolated by Trizolreagent (Invitrogen, Carlsbad, CA, USA) according to the user's guide specifically for short RNAs. Briefly, cells were homogenized by RNApro reagent. After phase separation by chloroform, 2.5 volume of alcohol was added to the aqueous phase to precipitate total RNA containing short RNA. Total RNA was then recovered by centrifuge and dissolved in nuclease-free water. Two micrograms of total RNA was tailed and reverse transcribed by NCode $^{\mathrm{TM}}$ EXPRESS SYBR $^{\odot}$ GreenER $^{\mathrm{TM}}$ miRNA qRT-PCR Kit (Invitrogen, Carlsbad, CA, USA) according to the user's manual. Quantitative real-time PCR was performed by miRNA specific primers (Additional file 1: Table S1). All Ct values of miRNAs were normalized 


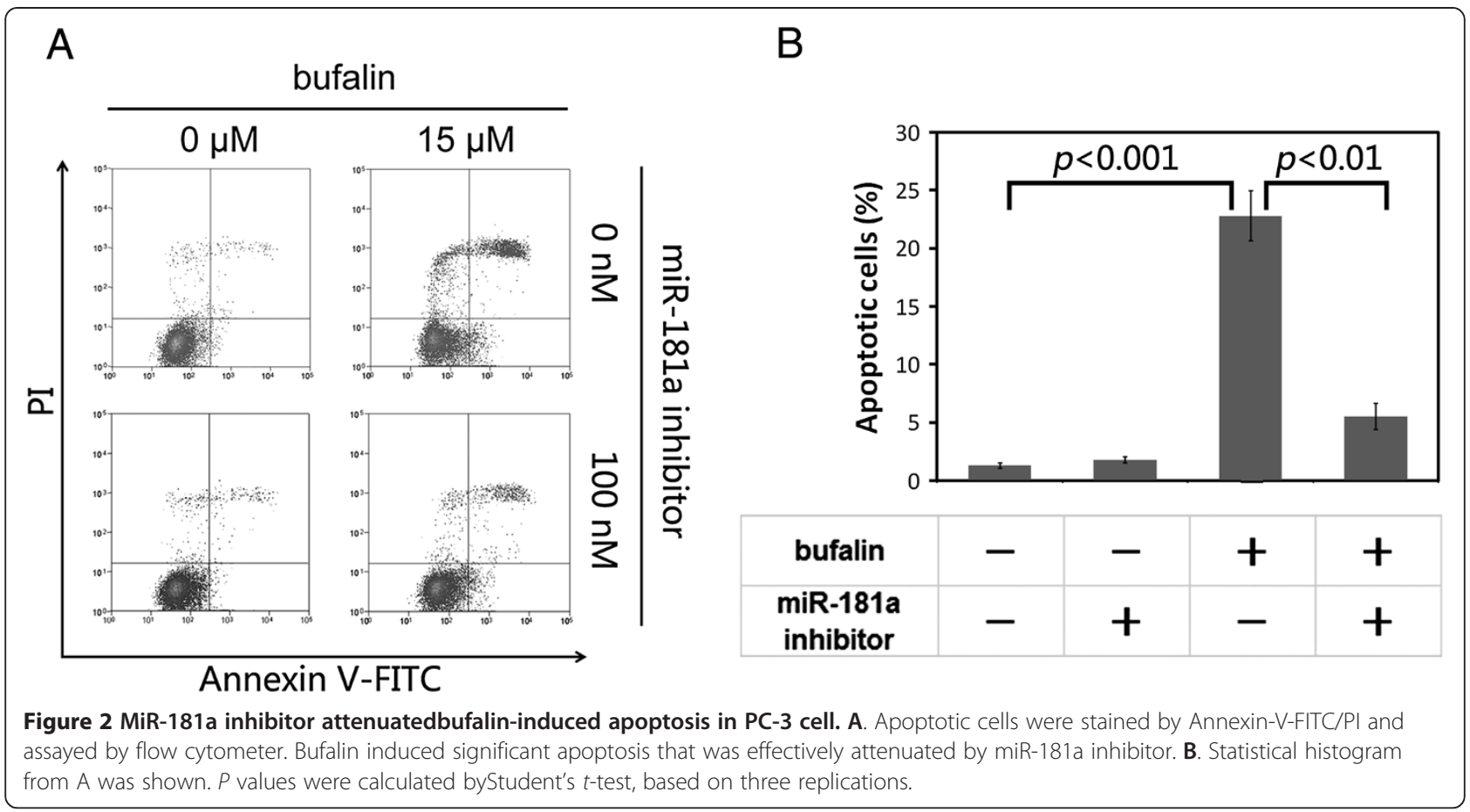

to $18 \mathrm{~S}$ rRNA. The $2^{-\Delta \Delta \mathrm{Ct}}$ method was used to calculate relative expression level of miRNAs.

\section{Apoptosis assay}

The apoptosis assay was performed with an annexin-V-FITC apoptosis detection kit (Sigma-Aldrich, St. Louis, MO, USA) according to the user's manual. Cells after different time treatments were washed by twice with PBS (Phosphate Buffered Saline) buffer. Cells were then resuspended in $1 \times$ binding buffer at a concentration of $\sim 1 \times 10^{6}$ cells $/ \mathrm{ml}$, and $5 \mu \mathrm{l}$ of Annexin V FITC conjugate and $10 \mu \mathrm{l}$ of propidium iodide (PI) solution were added to each $500-\mu \mathrm{l}$
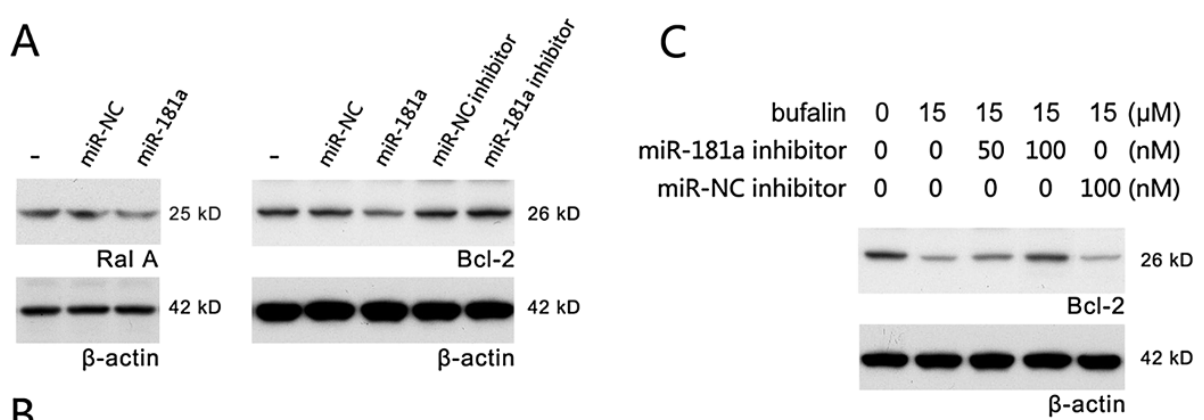

B

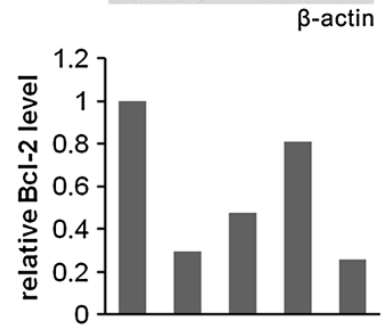

Figure 3 MiR-181a inhibitor blocked bufalin-induced Bcl-2 reduction in PC-3 cell. A. MiR-181a could repress the expression of $B C l-2$ and RalA. B. Bufalin reduced BCl-2 protein in a dose-dependent manner. The relative level of Bcl-2 protein in the western blot was normalized to $\beta$-actin and was shown in right panel. C. Bufalin-induced BCl-2 reduction was largely blocked by miR-181a inhibitor transfection. The relative level of $\mathrm{BCl}-2$ protein in the western blot was normalized to $\beta$-actin and was shown in lower panel. $\beta$-actin served as internal control; miR-NC indicated a negative miRNA control. 


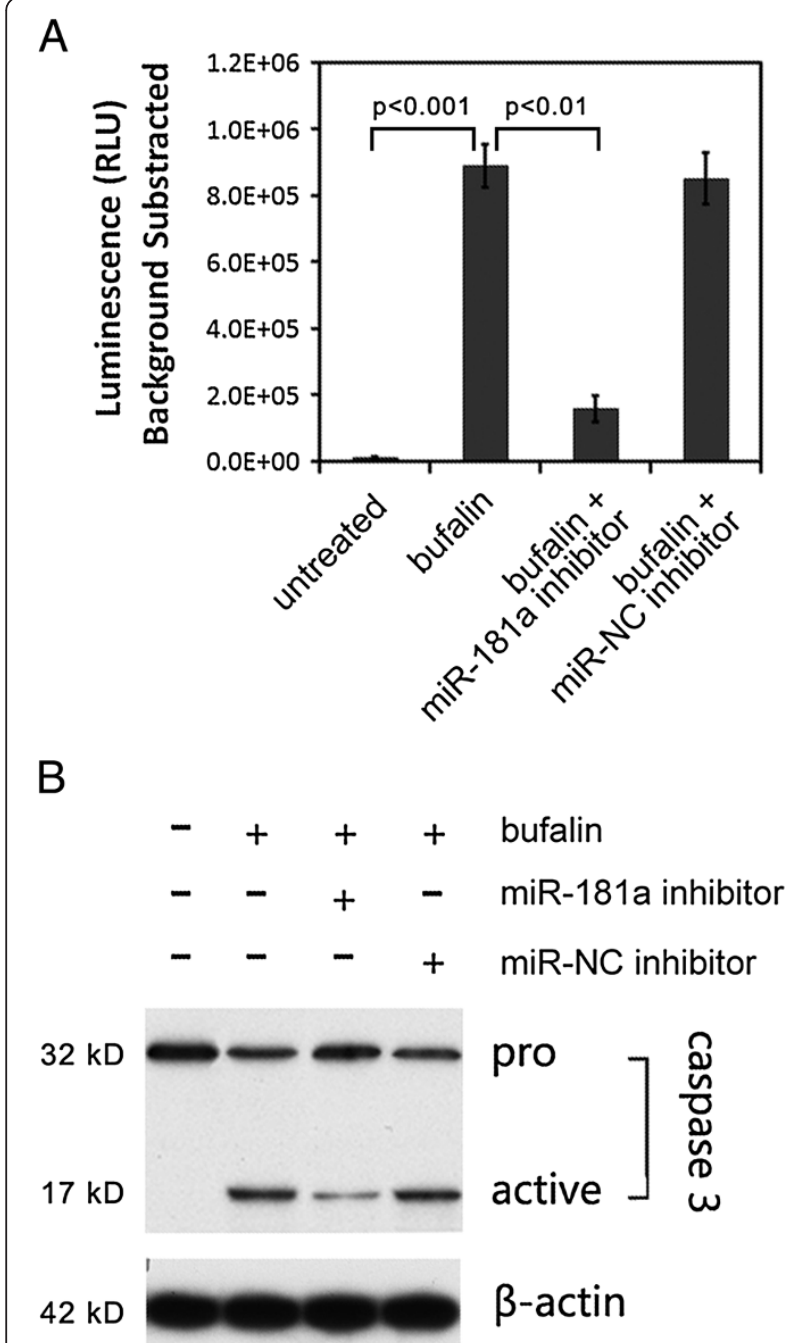

Figure 4 Bufalin-induced caspase-3 activity was reduced by miR-181a inhibitor transfection in PC-3 cell. A. Caspase-3 activity was assayed by a caspase-3 substrate cleavage based luminescence kit. Histogram showed the background subtracted luminescence value. $P$ values were calculated byStudent's $t$-test, based on three replications. B. Western blot showed that the active form of caspase-3 was reduced by miR-181a inhibitor transfection. $\beta$-actin served as internal control; miR-NC indicated a negative miRNA control.

cell suspension. Cells were stained by Annexin-V-FITC/PI for $10 \mathrm{~min}$ at room temperature. Stained samples were analyzed using MoFlo XDP flow cytometer (Beckman Coulter, Brea, CA, USA) and the apoptosis rate was determined using Flowjo software (Tree Star, Ashland, OR, USA).

\section{Western blotting}

Cells were washed with PBS and lysed in RIPA buffer. Cell lysate aliquots $(10 \mu \mathrm{g})$ were separated on a $10 \%$ SDS-PAGE gel and transferred to PVDF membrane. Primary antibodies for Bcl-2, Caspase-3, RalA and $\beta$-actin were purchased from Abcam (Abcam, Cambridge, MA, USA). Secondary antibody coupled with HRP was from Sigma (Sigma-Aldrich, St. Louis, MO, USA). Membrane was visualized by ECL PicoLightChemiluminescence kit (Promoton, Shanghai, China). Membrane was then exposed to X-ray film in dark room.

\section{Caspase-3 activity assay}

Caspase- 3 activity assay was performed by Caspase-Glo ${ }^{\circ}$ 3/7 Assay kit (Promega, Madison, WI, USA) in 96-well plate according to the user's manual. Luminescence was measured on a Mithras Multimode Microplate Reader LB 940 (Berthold, Calmbacher, Germany).

\section{Results}

\section{Bufalin induced the expression of miR-181a}

To test if certain miRNAs are involved in bufalininduced anti-tumor activity, two sets of cancer-related miRNAs-oncogenes (Figure 1A), and so-called tumor suppressors (Figure 1B)-were screened by quantitative real-time PCR in PC-3 cells after bufalin treatment, at aconcentration of $10 \mu \mathrm{M}$ [9-11,22]. Bufalin showed no significant effects on 10 screened oncogenicmiRNAs (Figure 1A). In the second set of miRNAs, which usually act as tumor suppressors, expression level of two miRNAs increased after bufalin treatment (Figure 1B). MiR-181a increased more than fivefolds compared to its basal expressionlevel, whereas miR-15a only increased by $\sim 50 \%$. We focused on miR-181a because it is the most significant induced miRNA in our study. We further determined miR-181a levels to be induced at different bufalin concentrations. MiR-181a expression was significantly induced by bufalin in a dose-dependent manner (Figure 1C). The miR-181a level was induced to nearly eight foldsas its basal level after treatment by bufalin at a concentration of $15 \mu \mathrm{M}$.

\section{MiR-181a inhibitor attenuated bufalin-induced apoptosis} Both bufalin and miR-181a could induce apoptosis in various cancer cells [4-7,14-21,23-26]. As bufalin can induce miR-181a expression, we speculated that bufalin-induced apoptosis may be mediated, at least partly, by miR-181a. To address this point, we tried to use miR-181a inhibitor to block bufalin-induced apoptosis. Bufalin treatment resulted in a $22.8 \%$ apoptosis rate in PC-3 cells, whereas the apoptosis rate decreased to $5.5 \%$ in cells transfected with miR-181a inhibitor (Figure 2). These data indicated that inhibition of miR-181a activity could attenuate bufalininduced apoptosis in PC-3 cells.

\section{MiR-181a inhibitor can reverse bufalin-induced $\mathrm{Bcl}-2$ decrease}

MiR-181a was believed to induce apoptosis by repressing its target genes, Bcl-2and RalA [14-21]. Transfection of 
miR-181a was shown to significantly down-regulate Bcl-2 and RalA protein (Figure 3A). Similarly, bufalin treatment decreasedBcl-2 proteinin a dose-dependent manner (Figure $3 \mathrm{~B}$ ); at $15 \mu \mathrm{M}$ of bufalin, $\mathrm{Bcl}-2$ protein level reduced by about $70 \%$. Furthermore, miR-181a inhibitor can reverse bufalin-induced Bcl-2 reduction (Figure 3C). Transfection with $100 \mu \mathrm{Mof}$ miR-181a inhibitor raised Bcl-2 protein to $\sim 80 \%$ of normal level. Anegative control inhibitor showed no reverse effect on Bcl-2 protein level after bufalin treatment. These results indicated that induced miR-181a mediates downstream bufalin-induced apoptosis by repressing Bcl-2 protein in PC-3 cells.

\section{MiR-181a inhibitor can reduce bufalin-induced caspase-3 activity}

$\mathrm{Bcl}-2$ is an anti-apoptosis protein and its decrease usually triggers mitochondrion mediated apoptosis pathway by caspase-3 proteins activation. Therefore, we also assayed caspase- 3 activity by cleavage of aminoluciferin-coupled caspase-3 substrate in lysate of PC-3 cells treated with or without bufalin. Upon caspase-3 activation, aminoluciferincoupled caspase- 3 substrate was cleaved and aminoluciferin, a substrate of luciferase, is released, resulting in the luciferase reaction and production of luminescence. After bufalin treatment, miR-181a inhibitor transfected cell lysate, showed only $\sim 20 \%$ caspase-3 activity when compared with untransfected lysate; whereas transfection with a negative control inhibitor did not reduce bufalin-induced caspase-3 activity (Figure 4A). The cell lysates were further subjected to western blot analysis with a caspase- 3 antibody that recognizes both pro- and cleaved caspase- 3 . After bufalin treatment, pro-caspase- 3 was cleaved to a smaller active form that can lead to apoptosis. MiR-181a inhibitor, however, largely reduced the activating cleavage of pro-caspase- 3 and the level of the active form of caspase- 3 (Figure 4B).

\section{Discussion}

Cinobufacini, is a form of traditional Chinese medicine, and has been approved by the Chinese State Food and Drug Administration (SFDA) for many years. Cinobufacini injection is widely used in China to treat patients with various cancers [27]. Many clinical trials have shown it to effectively shrink lesions and improve patients' survival rate and quality of life. Bufalin, as a major active compound of cinobufacini, was considered to have great effect on tumors, including inhibition of proliferation and cancer angiogenesis, induction of differentiation and apoptosis, disruption of cell cycle, reversal of multi-drug resistance, and regulation of immune response [6]. Although various studies present the mechanism by which bufalin induces apoptosis in cancer cells, the anti-tumor activity of bufalin and miRNAs in inducing miR-181a expression had not been shown before this study.
Many miRNAs regulate various processes in tumorigenesis, including apoptosis and metastasis, and have received increasing attention in cancer research. To test if miRNA pathways crosstalk with the pharmacologic action of bufalin in cancers, we screened expression of some cancer-related miRNAs in PC-3 cells after bufalin treatment, and observed miR-181a expression to significantly increase in a dose-dependent manner. We also showed miR-181 to induce significant apoptosis through down-regulation of Bcl-2 protein. Furthermore, miR-181a inhibitor largely attenuated bufalin-induced apoptosis. Our results indicate that miR-181a mediates a downstream, bufalin-induced apoptosis pathway, and suggest a more detailed model for bufalin-induced apoptosis in which bufalin induces expression of miR-181a, which in turn inhibits Bcl-2 protein, resulting in apoptosis.

\section{Conclusions}

Based on our result, we presented here a more detailed model for bufalin-induced apoptosis. Bufalin treatment induced the expression of miR-181a, which in turn inhibited $\mathrm{Bcl}-2$ protein and resulted in cell apoptosis.

\section{Additional file}

Additional file 1: Table S1. Primers used in this study.

\section{Competing interests}

The authors have no actual or potential conflict of interest associated with this work.

\section{Authors' contributions}

XFZ, FFF and ZC participated in the design of the study data analyses and manuscript preparation. QL, YBM, YYG and FFF conducted the assays and analyses. All authors read and approved the final manuscript.

\section{Acknowledgement}

This work was supported by Shanghai Municipal Health Bureau (ZYSNXD - CC - ZDYJ032).

Author details

'Department of Integrative Oncology, Changhai Hospital of Traditional Chinese Medicine, Second Military Medical University, Shanghai 200433, China. ${ }^{2}$ Department of Rehabilitation Medicine, Changhai Hospital of Traditional Chinese Medicine, Second Military Medical University, Shanghai 200433, China.

Received: 21 July 2013 Accepted: 18 November 2013

Published: 23 November 2013

\section{References}

1. Yang $L H$, Jin $X Q$, Zhang WD: Studies on the chemical constituents from the skin of Bufo bufo gargarizans cantor. Journal of Shenyang Pharmaceutical University 2000, 17:292-295.

2. Qi FH, Li AY, Inagaki Y, Kokudo N, Tamura S, Nakata M, Tang W: Antitumor activity of extracts and compounds from the skin of the toad Bufo bufo gargarizans Cantor. Int Immunopharmacol 2010, 11:342-349.

3. Li D, Qu X, Hou K, Zhang Y, Dong Q, Teng Y, Zhang J, Liu Y: PI3K/Akt is involved in bufalin-induced apoptosis in gastric cancer cells. Anticancer Drugs 2009, 20:59-64. 
4. Yu CH, Kan SF, Pu HF, Jea Chien E, Wang PS: Apoptotic signaling in bufalin- and cinobufagin-treated androgen-dependent and -independent human prostate cancer cells. Cancer Sci 2008, 99:2467-2476.

5. Sun $L$, Chen $T$, Wang $X$, Chen $Y$, Wei $X$ : Bufalin induces reactive oxygen species dependent bax translocation and apoptosis in ASTC-a-1 Cells. Evid Based Complement Alternat Med 2011, 2011:249090.

6. Han KQ, Huang G, Gu W, Su YH, Huang XQ, Ling CQ: Anti-tumor activities and apoptosis-regulated mechanisms of bufalin on the orthotopic transplantation tumor model of human hepatocellular carcinoma in nude mice. World J Gastroenterol 2007, 13:3374-3379.

7. Takai N, Ueda T, Nishida M, Nasu K, Narahara H: Bufalin induces growth inhibition, cell cycle arrest and apoptosis in human endometrial and ovarian cancer cells. Int J Mol Med 2008, 21:637-643.

8. Mo YY: MicroRNA regulatory networks and human disease. Cell Mol Life SCi 2012, 69:3529-3531.

9. Garzon R, Calin GA, Croce CM: MicroRNAs in Cancer. Annu Rev Med 2009, 60:167-179

10. Li MF, Li J, Ding XF, He M, Cheng SY: microRNA and cancer. AAPS J 2010, 12:309-317.

11. Ruan K, Fang XG, Ouyang GL: MicroRNAs: novel regulators in the hallmarks of human cancer. Cancer Lett 2009, 285:116-126.

12. Chen CZ, Li L, Lodish HF, Bartel DP: MicroRNAs modulate hematopoietic lineage differentiation. Science 2004, 303:83-86.

13. Shi L, Cheng ZH, Zhang JX, Li R, Zhao P, Fu Z, You YP: hsa-mir-181a and hsa-mir-181b function as tumor suppressors in human glioma cells. Brain Res 2008, 1236:185-193.

14. Ouyang YB, Lu Y, Yue S, Giffard RG: miR-181 targets multiple Bcl-2 family members and influences apoptosis and mitochondrial function in astrocytes. Mitochondrion 2011, 12:213-219.

15. Bai H, Cao Z, Deng C, Zhou L, Wang C: miR-181a sensitizes resistant leukaemia HL-60/Ara-C cells to Ara-C by inducing apoptosis. J Cancer Res Clin Oncol 2012, 138:595-602.

16. Chen G, Zhu W, Shi DZ, Lv L, Zhang C, Liu P, Hu WX: MicroRNA-181a sensitizes human malignant glioma U87MG cells to radiation by targeting Bcl-2. Oncol Rep 2010, 23:997-1003.

17. Galluzzi L, Morselli E, Vitale I, Kepp O, Senovilla L, Criollo A, Servant N, Paccard C, Hupe $P$, Robert T, et al: miR-181a and miR-630 regulate cisplatin-induced cancer cell death. Cancer Res 2010, 70:1793-1803.

18. Li H, Hui LL, Xu WL: miR-181a sensitizes a multidrug-resistant leukemia cell line K562/A02 to daunorubicin by targeting BCL-2. Acta Biochim Biophys Sin (Shanghai) 2012, 44:269-277.

19. Zhu DX, Zhu W, Fang C, Fan L, Zou ZJ, Wang YH, Liu P, Hong M, Miao KR, Xu W, Li JY: miR-181a/b significantly enhances drug sensitivity in chronic lymphocytic leukemia cells via targeting multiple anti-apoptosis genes. Carcinogenesis 2012, 33:1294-1301.

20. Zhu W, Shan X, Wang TS, Shu YQ, Liu P: miR-181b modulates multidrug resistance by targeting $B C L 2$ in human cancer cell lines. Int J Cancer 2010, 127:2520-2529.

21. Fei J, Li Y, Zhu X, Luo X: miR-181a post-transcriptionally downregulates oncogenic RalA and contributes to growth inhibition and apoptosis in chronic myelogenous leukemia (CML). PLoS One 2012, 7:e32834.

22. Cho WC: MicroRNAs in cancer - from research to therapy. Biochim Biophys Acta 1805, 2009:209-217.

23. Masuda Y, Kawazoe N, Nakajo S, Yoshida T, Kuroiwa Y, Nakaya K: Bufalin induces apoptosis and influences the expression of apoptosis-related genes in human leukemia cells. Leuk Res 1995, 19:549-556.

24. Watabe M, Masuda Y, Nakajo S, Yoshida T, Kuroiwa Y, Nakaya K: The cooperative interaction of two different signaling pathways in response to bufalin induces apoptosis in human leukemia U937 cells. J Biol Chem 1996, 271:14067-14072.

25. Watabe M, Ito K, Masuda Y, Nakajo S, Nakaya K: Activation of AP-1 is required for bufalin-induced apoptosis in human leukemia U937 cells. Oncogene 1998, 16:779-787.
26. Watabe M, Kawazoe N, Masuda Y, Nakajo S, Nakaya K: Bcl-2 protein inhibits bufalin-induced apoptosis through inhibition of mitogen-activated protein kinase activation in human leukemia U937 cells. Cancer Res 1997, 57:3097-3100.

27. Zhai XF, Chen Z, Li B, Shen F, Fan J, Zhou WP, Yang YK, Xu J, Qin X, Li LQ, Ling CQ: Traditional herbal medicine in preventing recurrence after resection of small hepatocellular carcinoma: a multicenter randomized controlled trial. J Integr Med 2013, 2:90-100.

doi:10.1186/1472-6882-13-325

Cite this article as: Zhai et al:: MiR-181a contributes to bufalin-induced apoptosis in PC-3 prostate cancer cells. BMC Complementary and Alternative Medicine 2013 13:325

\section{Submit your next manuscript to BioMed Central and take full advantage of:}

- Convenient online submission

- Thorough peer review

- No space constraints or color figure charges

- Immediate publication on acceptance

- Inclusion in PubMed, CAS, Scopus and Google Scholar

- Research which is freely available for redistribution

Submit your manuscript at www.biomedcentral.com/submit
C BioMed Central 